sexes with delayed puberty had normal LH and FSH release when tested, suggesting that hypothalamic or higher centres are involved in the initiation of puberty.

In patients with "functionless" pituitary tumours or those with active acromegaly, impaired $\mathrm{LH}$ release was often seen, though FSH reserve under the test conditions appeared intact. The ability of the pituitary to release gonadotrophins occurred in many patients independently of the functional pituitary reserve for other hormones. The three patients with pituitarydependent Cushing's disease each showed a different type of response-normal, impaired, or exaggerated. Impaired or absent TSH responses to TRH were seen in these three patients and this is characteristic of this condition (Hall et al., 1972).

When the 15 patients with amenorrhoea and galactorrhoea were investigated it was clear that basal gonadotrophin levels were normal or high in nine, and that normal or even exaggerated responses could occur after administration of the decapeptide. The response did not correlate with basal prolactin levels nor the levels achieved after administration of TRH. The cause of amenorrhoea in these women was clearly not due to inability to synthesize the gonadotrophins but was probably the result of failure of their cyclical release. Hyperprolactinaemia may be responsible, at least in part, for this functional abnormality, since when the prolactin levels were reduced with bromergocryptine galactorrhoea ceased and normal menstruation resumed; potency returned in male patients similarly treated (Besser et al., 1972 b). Whether prolactin interferes at the hypothalamic-pituitary level or has a direct action on the gonads remains to be elucidated.

Gonadotrophin releasing hormone responsiveness was present in every patient with anorexia nervosa, and here again it is probably the failure of cyclical release rather than inability to synthesize gonadotrophins which is the major factor in the initiation and perpetuation of the amenorrhoea. Patients with primary gonadal failure showed the expected exaggerated response to the decapeptide.

In view of the fact that in most patients with hypogonadotrophic hypogonadism, of whatever cause, LH and FSH secretion can be induced with the synthetic decapeptide LH/FSH-
$\mathrm{RH}$, it is evident that the pituitaries of these patients contain $\mathrm{LH}$ and FSH. It would therefore appear that it is the impairment of release which is the primary cause of the hypogonadism rather than pituitary gonadotroph destruction in these patients. It is disappointing that the $\mathrm{LH} / \mathrm{FSH}-\mathrm{RH}$ test will not differentiate between hypothalamic and pituitary causes of hypogonadotrophic hypogonadism. However, since such a high proportion of these patients can be made to release $\mathrm{LH}$ and FSH in response to the decapeptide, it is possible that repeated administration of $\mathrm{LH} / \mathrm{FSH}-\mathrm{RH}$ might restore their fertility, and the results of therapeutic trials with this material are awaited.

Requests for reprints should be addressed to: Dr. G. M. Besser, Medical Professorial Unit, St. Bartholomew's Hospital, London EC1A 7BE.

\section{References}

Anderson, D. C. (1970). Clinica Chimica Acta, 29, 513

Besser, G. M., McNeilly, A. S., Anderson, D. C., Marshall, J. C., Harsoulis, P., Hall, R., Ormston, B. J., Alexander, L., and Collins, W. P. (1972 a). British Medical fournal, 3, 267.

Besser, G. M., Parke, L., Edwards, C. R. W., Forsyth, I. A., and McNeilly, A. S. (1972 b). British Medical fournal, 2, 669.

Hall, R., Amos, J., and Ormston, B. J. (1971). British Medical fournal, 1, 582 Hall, R., Ormston, B. J., Besser, G. M., Cryer, R. J., and McKendrick, M. (1972). Lancet, 1, 759.

Hartog, M., Gaafar, M. A., Meisser, B., and Fraser, T. R. (1964). British Medical fournal, 2, 1229.

Matsuo, H., Baba, Y., Nair, R. M. G., Arimura, A., and Schally, A. V. (1971). Biochemical and Biophysical Research Communications, 43, 1334 Marshall, J. C., Harsoulis, P., Anderson, D. C., McNeilly, A. S., Besser G. M., and Hall, R. (1972). British Medical fournal, 4, 643.

McNeilly, A. S. (1973). Proceedings of the Royal Society of Medicine, 66, 863 Mattingly, D. (1962). Fournal of Clinical Pathology, 15, 374.

Mortimer, C. H., Besser, G. M., McNeilly, A. S., Tunbridge, W. M. G., Gomez-Pan, A., and Hall, R. (1973). Clinical Endocrinology. In press.

Ormston, B. J., Cryer, R. J., Garry, R., Besser, G. M., and Hall, R. (1971)

Lancet, 2, 10 .
Schally, A. V., Baba, Y., Arimura, A., Redding, T. W., and White, W. F. (1971 a). Biochemical and Biophysical Research Communications, 42, 50. Schally, A. V., Arimura, A., Baba, Y., Nair, R. M. G., Matsuo, H., Redding, T. W., Debeljuk, L., and White W. F. (1971 b). Biochemical and Biophysical Research Communications, 43, 393.

Schally, A. V., Arimura, A., Kastin, A. J., Matsuo, H., Baba, Y., Redding T. W., Nair, R. M. G., and Debeljuk, L. (1971 c). Science, 173, 1036.

\title{
Fertility after Unilateral Orchidectomy and Radiotherapy for Patients with Malignant Tumours of the Testis
}

\author{
D. W. SMITHERS, D. M. WALLACE， D. E. AUSTIN
}

British Medical fournal, 1973, 4, 77-79

\section{Summary}

The results of treatment for patients with seminoma of the testis by orchidectomy and irradiation are so satisfactory that retroperitoneal lymph node dissection is no longer practised. However, this operation is still used routinely in some centres for patients with testicular teratomas despite the lack of evidence that it gives better results than those obtained with irradiation followed by removal of lymphographically demonstrable residual

Testicular Tumour Unit, Royal Marsden Hospital, Sutton, Surrey Sir David SMITHERS, M.D., F.R.C.s., Director of Radiotherapy Department D. M. WALLACE, M.s., Urological Surgeon D. E. AUSTIN, Records Officer tumour and in the face of the high incidence of ejaculatory impotence which follows. On grounds of preservation of sexual function and fertility there is a great advantage to be gained from the latter form of treatment. Thirty-four of our patients between the ages of 25 and 45 years treated by irradiation to the para-aortic and iliac nodes for testicular tumours fathered 52 children to term after their treatment.

\section{Introduction}

In previous publications (Smithers and Wallace, 1962; Smithers et al., 1971; Smithers, 1972) we have reported our results in 446 patients with tumours of the testis treated before 1968 (255 seminomas, 191 teratomas). At least $95 \%$ with seminomas of the testis should be cured today by orchidectomy and irradiation, and there is no indication for radical node dissection in these patients. 


\section{Results}

The results of retroperitoneal node dissection in patients with teratomas of the testis, with and without irradiation, reported by Whitmore (1970) and Walsh et al. (1971) are shown in table I, and table II gives our own results in 143 patients with teratomas after irradiation when the surgery for the lymph nodes was confined to the removal of residual tumours seen on lymphography.

TABLE I-Survival of Patients in Series of Whitmore (1970) and Walsh et al. (1971) Treated by Node Dissection with and without Radiotherapy (Clinical Stage I)

\begin{tabular}{|c|c|c|c|c|c|}
\hline \multirow[b]{2}{*}{$\begin{array}{l}\text { Nodes negative } \\
\text { Nodes positive } \\
\end{array}$} & \multirow[b]{2}{*}{$\therefore$} & \multicolumn{2}{|c|}{$\begin{array}{l}\text { Whitmore (1970) } \\
\text { Collected Series } \\
\text { (5-year Survival) }\end{array}$} & \multicolumn{2}{|c|}{$\begin{array}{l}\text { Walsh et al. (1971) } \\
\text { (3-year Survival) }\end{array}$} \\
\hline & & $\begin{array}{r}164 / 204 \\
78 / 159 \\
\end{array}$ & $\begin{array}{l}(80 \%) \\
(49 \%)\end{array}$ & $\begin{array}{l}41 / 44 \\
12 / 20\end{array}$ & $\begin{array}{l}(93 \%) \\
(60 \%) \\
\end{array}$ \\
\hline & & $242 / 363$ & $(66 \%)$ & $53 / 64$ & $(83 \%)$ \\
\hline
\end{tabular}

TABLE II-Survival of Patients in Royal Marsden Hospital Series treated by Radiotherapy with Surgery Confined to Removal of Residual Tumour seen on Lymphogram (Lymphographic Stages I and II).

\begin{tabular}{|c|c|c|c|c|}
\hline \multirow[b]{2}{*}{$\begin{array}{l}\text { Lymphogram negative } \\
\text { Lymphogram positive .. }\end{array}$} & \multirow[b]{2}{*}{. } & \multirow[b]{2}{*}{$\because$} & \multicolumn{2}{|c|}{$\begin{array}{c}\text { Royal Marsden Hospital Series } \\
\text { (Smithers, 1972) }\end{array}$} \\
\hline & & & $\begin{array}{l}25 / 27 \\
10 / 16\end{array}$ & $\begin{array}{l}(93 \%) \\
(63 \%)\end{array}$ \\
\hline & & & $35 / 43$ & $(81 \%)$ \\
\hline
\end{tabular}

Such comparisons of series with different selections treated in different centres at different times are unreliable. The data in table I, however, at least leaves the question open as to whether radical node dissection is justifiable as a routine procedure in patients with teratomas of the testis. It seems to us, on present evidence, that this operation is unjustifiable without a positive lymphogram. Even when the lymphogram gives a positive result, controlled trials of retroperitoneal lymphadenectomy in selected groups, particularly the intermediate teratomas (teratocarcinomas), are required before the value of this procedure can be assessed.

\section{EFFECT OF TREATMENT ON SEXUAL FUNCTION}

One of the main objections to routine node dissection is that most of these patients suffer thereafter from ejaculatory impotence and are sterile (75\% in Walsh et al., 1971). After retroperitoneal node dissection in nine patients aged 20 to 34 years, two of whom were married with children before treatment, Kom et al. (1971) found that six had ejaculatory impotence and three had a visible ejaculate of markedly decreased volume. In two of these there were normal sperms present. Our patients treated by irradiation have no ejaculatory impotence and may be fertile. There are centres, however, where the remaining testis is irradiated prophylactically, resulting in infertility but not necessarily in erectile or ejaculatory impotence.

The dose of radiation to the testes with the L-shaped abdominal fields used by us on the 6 or $8 \mathrm{MeV}$ linear accelerators, depends largely on whether the inguinal nodes have to be irradiated or not. This is rarely necessary except when natural or surgical spread to the scrotum has occurred. Sharp definition of the irradiated volume is possible with the fine-focus tubes of the accelerators and lead block screening, providing a definite improvement over ${ }^{6}{ }^{\circ} \mathrm{Co}$ treatment. To reduce the dose from internally scattered radiation a testicular shield consisting of two cups of $1 \mathrm{~cm}$ moulded lead is added. Many of our patients have now had their testicular doses measured during treatment using the thermoluminescent phosphor lithium fluoride (TLD 100). This investigation has shown that without extending the field to the inguinal region the testicular dose with our tech- nique is about $1.5 \%$ of the nodal dose so that a testicular dose of between 50 and 70 rads is to be expected for a nodal dose of 4,000 rads in three to five weeks. When the inguinal nodes are also treated the testicular dose rises to about $2.5 \%$ of the nodal dose (90 to 110 rads per 4,000 rads nodal dose). Testicular doses without the extra cup shields are more than double those given above, both with and without inguinal irradiation (about 250 rads and 150 rads per 4,000 rads respectively).

Such dose levels may lead to sterility but the frequency with which they do so cannot be assessed without information both about the fertility of males destined to develop testis tumours and about their contraceptive practice. Orecklin et al. (1973) found from 77 responses to a questionnaire sent to 101 patients treated for malignant tumours of the testis that 52 said they had attempted to father a child before treatment and that $42(81 \%)$ had been successful. A study by semen analysis was made on seven men with testicular tumours by Amelar et al. (1971). Four had normal fertility levels before orchidectomy and irradiation, all had extremely poor semen quality after treatment but were restored to normal levels in three to four years, and three of them fathered normal children. The other patients had poor semen quality before treatment, became azoospermic after treatment, but had returned to their former poor semen quality within four years.

In the Orecklin et al. (1973) survey, 28 patients had attempted to father a child after treatment and $18(65 \%)$ had been successful. Sixteen of these 18 had been irradiated, two had not. Of the 10 who failed one had been irradiated and nine had had a retroperitoneal lymph node dissection; five of them had ejaculatory impotence. One mongoloid child was born to a patient in the irradiated group but both parents were in their late 30's.

\section{FERTILITY IN OUR TREATED PATIENTS}

Detailed family histories were not always taken in the early days, and our information about these families is certainly weighted in favour of parents. However, one statement about fertility can be made-namely, that we have records of 34 men who have fathered 52 children after orchidectomy and irradiation for malignant disease of the testis. In none of these children was there any evidence of teratogenic changes.

\section{STUDY OF 74 PATIENTS (49 WITH SEMINOMA, 25 WITH TERATOMA)}

The age and previous family histories of patients affects the probability of their having children after treatment. Our group has, therefore, been divided by age as follows.

25 and Under (8 Patients).-Five had eight children conceived and born after treatment (no children recorded before onset of tumour); one fathered a normal fetus, medically terminated (neither parent married); one had two children before treatment and had a second primary in the other testis six years later; one fertile shortly before diagnosis (wife pregnant when he first came to hospital) is alive and disease-free at 10 years, but we have no record of any further family.

26-30 Years (24 Patients). - Nineteen had 32 children conceived and born after treatment, four of whom had five children before onset of tumour; one fathered a miscarriage after treatment, having had no children before onset of tumour; three were fathers before onset of tumour, having three, two, and two children respectively, without record of whether families were then limited by choice; one known to be unsuccessful before and after tumour onset.

31-35 Years (11 Patients). - Seven had eight children conceived and born after treatment, three of whom were fathers before onset of tumour, having three, two, and one children respectively; three were fathers before onset of tumour, having three, three, and two children respectively and no children after treatment without record of whether families were then limited by choice; one had no children and was not married until one 
year after first primary; he had a second primary in the other testis four years after marriage.

36-40 Years (9 Patients). - Two had three children conceived and born after treatment, one of whom already had three children; seven had 12 children before onset of tumour, three of whom were known to have then limited their family by choice.

41-45 Years (6 Patients).-One had a child after treatment, none before. Four were fathers before onset of tumour, having nine children. One known to have then limited the family by choice; one adopted a child after treatment, having no family before onset of tumour.

46 Years and Over (16 Patients).-Fourteen were fathers of 26 children before onset of tumour; one was fertile before treatment (miscarriage) and then a prisoner of war for five years and had a wife much older than himself; one was fertile before treatment (wife had a miscarriage followed by hysterectomy).

The time of conception ranged from during treatment in one patient and five months after treatment in another (despite the warnings given) to 12 years after treatment. Most of these patients conceived their children within a two-to three-year interval after the irradiation but there was a gap before the first child was born of four, five, six, eight, 11 , and 12 years in other cases. All these children appear normal. Twenty-seven were born to patients who had had seminomas and 25 to those who had had teratomas.
The risks of transmitting radiation-induced chromosomal abnormalities may be high in the immediate postradiation period if damaged spermatozoa are still viable, but a period of sterility or subfertility lasting a few months to a few years may follow the irradiation. We tell patients who have been irradiated for testis tumours that they should avoid parenthood during or directly after treatment and advise them to wait for at least a year.

We are grateful to Miss Margot Hannam, superintendent radiographer, for keeping the records of children for our Testicular Tumour Unit.

\section{References}

Amelar, R. D., Dubin, L., and Hotchkiss, R. S. (1971). Fournal of Urology, 106, 714 .

Kom, C.., Mulholland, S. G., and Edson, M. (1971). Fournal of Urology, $105,528$.

Orecklin, J. R., Kaufman, J. J., and Thompson, R. W. (1973). Fournal of Urology, 109, 293.

Smithers, D. W., and Wallace, E. N. K. (1962). British Fournal of Urology, 34,422 .

Smithers, D. W., Wallace, E. N. K., and Wallace, D. M. (1971). British fournal of Urology, 43, 83.

Smithers, D. W. (1972). Fournal of the Royal College of Surgeons of Edinburgh, 17, 133 .

Walsh, P. C., Kaufman, J. J., Coulson, W. F., and Goodwin, W. E. (1971) Fournal of the American Medical Association, 217, 309.

Whitmore, W. F., jun. (1970). Sixth National Cancer Conference Proceedings, p. 219. Philadelphia, Lippincott.

\title{
Vagotomy or Gastrectomy for Gastric Ulcer
}

\author{
H. L. DUTHIE， N. K. KWONG
}

British Medical fournal, 1973, 4, 79-81

\section{Summary}

Patients treated in a randomized controlled comparison of management of benign gastric ulcer of the body of the stomach, comprising 50 patients treated by Billroth I partial gastrectomy and 50 patients treated by vagotomy and pyloroplasty and biopsy of the ulcer, were followed up for about five years (range one and a half to eight and a half years). No statistically significant difference has been found between the functional results (Visick grading) of the two groups. There was no operative mortality. Postoperative morbidity (17 against 5 ) and length of stay in hospital (14 against 10 days) were significantly greater after gastrectomy. Seven patients after vagotomy have been submitted to gastrectomy (three for recurrent gastric ulceration, three for gastric cancer, and one for bleeding), which is a statistically significant excess compared with no reoperation after gastrectomy. While vagotomy and pyloroplasty can be useful to avoid a technically difficult gastrectomy, it cannot be said to replace partial gastrectomy in the treatment of gastric ulcer.

\section{Introduction}

In keeping with the general trend towards conservative surgery for peptic ulceration, we have been comparing vagotomy and

\footnotetext{
University Department of Surgery, The Royal Infirmary, Sheffield S6 3DA

H. L. DUTHIE, M.D., CH.M., Professor of Surgery

N. K. KWONG, M.D., F.R.C.S., Research Assistant
}

pyloroplasty with Billroth I gastrectomy in the surgical treatment of gastric ulceration. Initial results have been reported (Duthie et al., 1970). We now present longer-term follow-up which shows that the initial superiority of gastrectomy has not been maintained with the passage of time.

\section{Methods}

From 1964 to 1971100 consecutive cases of peptic ulceration of the body of the stomach, excluding emergency operations, have been included in a randomized controlled trial of the operation of vagotomy and pyloroplasty compared with Billroth I gastrectomy. The patient was entered into the trial when the diagnosis was confirmed at operation and no evidence of duodenal ulceration or of an ulcer within $2 \mathrm{~cm}$ of the pylorus was found. A biopsy of the ulcer was performed. Initially a four-quadrant biopsy specimen was taken but in the last 25 cases a circumferential specimen of the whole ulcer was obtained and sent for immediate histological examination. During this period seven cases (three selected for vagotomy, and four selected for gastrectomy) were found to have an ulcer/cancer and 100 cases had benign ulceration. The cases with ulcer/cancer are considered separately. Standard operative techniques were used. Truncal vagotomy was used in 41 cases and selective vagotomy in nine cases, each combined with a Heineke-Mikulicz pyloroplasty. About $50-60 \%$ of the stomach was removed at gastrectomy. The gastric remnant was anastomosed to the duodenum (Billroth I). Insulin tests were performed on patients with postoperative symptoms.

At follow-up patients were interviewed personally and particular note was made of any postoperative symptoms. Direct questions were asked concerning presence of diarrhoea, dumping, bilious vomiting, distension, and any dyspepsia. After full examination the patients were weighed, their height was meas- 